\title{
Fuzzy Scheduling Applied on Hydroelectric Power Generation
}

\author{
Carlos Gracios-Marin et al. ${ }^{*}$ \\ ${ }^{1}$ Benemérita Universidad Autónoma de Puebla, \\ Facultad de Ciencias de la Electrónica, Puebla, \\ México
}

\section{Introduction}

New industrial processes are evolution in terms of novel requirements to be accomplished. Interoperability, Open and Dynamic structures and Fault tolerance characteristics are some of them described by Shen and Norrie (1999).

In the environment of fault tolerance concept, it is desirable to reduce the effects of bad decision in the scheduling of activities/resources and to make good decision (adaptability) when one or more resources in the process fail.

In many application areas in which a malfunction of the system can cause significant losses or even endanger the environment or human life, a fault analysis model is required to evaluate the performance and can anticipate possible faults in the process defined by Zhuo and Venkatesh (1999).

Examples of such areas are in transport, process control and instrumentation with devices. The systems which are used in such or similar application areas are expected to exhibit always an acceptable behaviour. This property of a system is often referred to as dependability. Any departure from the acceptable behaviour is considered a system failure. Failures are caused by faults, which can arise in different phases of the manufacturing system lifecycle.

Most of the techniques which have been devised for fault analysis are targeted towards hard-wired systems and do not match the characteristics of software. A crucial difference between hardware and software system is that a program can neither break nor wear-out. Software faults can always be traced back to mistakes, which have been made during software specification, design or implementation.

To detect and remove faults, the software can be verified and validated against the requirements specification (model). The weakest point of this procedure is the requirements

* Gerardo Mino-Aguilar ${ }^{1}$, German A. Munoz-Hernandez' ${ }^{1}$ José Fermi Guerrero-Castellanos ${ }^{1}$, Alejandro Diaz-Sanchez ${ }^{1,2}$, Esteban Molina Flores and Eduardo Lebano-Perez ${ }^{1,3}$

${ }^{1}$ Benemérita Universidad Autónoma de Puebla, Facultad de Ciencias de la Electrónica Puebla, México

2 INAOE.- Tonantzintla, Puebla, México

${ }^{3}$ UPAEP.- Puebla, México 
specification. Any fault or ambiguity in the specification can result in a fault in the process implementation. Fault avoidance is another approach to increase process dependability.

Most of the measures applied throughout the development process attempt to make the development more strict and formal. It is important that the process of adding rigor and formality could start from the very beginning, i.e. from developing a formal requirements specification which defines the space of all behaviours, which can be exhibited by the software. In the next step the unacceptable, e.g. dangerous, behaviours can be identified and defined in terms of the same formalism. Finally, one can check whether an unacceptable behaviour can be deduced from the specification. If this is the case, the specification can be modified and the analysis repeated.

A special case arises, when the formal model which underlies a software specification is discrete. In such a case the space of all behaviours is discrete, and a definition of an unacceptable behaviour can be reduced to a definition of unacceptable states. The evaluation of the software behaviour can be conducted as verification whether or not such states belong to the state space of the specification.

\section{Background of concepts}

\subsection{Intelligent fault diagnosis}

Actual industrial processes must accomplish the new requirement by high performance characteristics. Interoperability, Open and Dynamic structures and Fault tolerance characteristics are examples of these requirements, described by Shen and Norrie (1999).

The fault tolerance concept, consider as desirable to reduce the effects of bad decision in the scheduling of activities/resources and to make good decision (adaptability) when one or more resources in the process fails.

In many applications in which a malfunction of the system can cause significant losses or even cause danger to the environment or human life, a fault analysis model is required to evaluate the performance and can anticipate possible faults in the process. Examples of such areas are in transport of material, process control and instrumentation with devices.

The systems which are used in such or similar application areas are expected to exhibit always an acceptable behaviour. This property of a system is often referred to as dependability. Any departure from the acceptable behaviour is considered a system failure. Failures are caused by faults, which can arise in different phases of the process system lifecycle.

By definition, a fault represents an unexpected change of system function, although it may not represent a physical failure. The term failure indicates a serious breakdown of a system component or function that leads to a significantly deviated behaviour of the whole system. The term fault rather indicates a malfunction that does not affect significantly the normal behaviour of the system considered in first time by Rzevski (1989) and Nasr (2007) actually.

An incipient (soft) fault represents a small and often slowly developing continuous fault. Its effects on the system are in the beginning almost unnoticeable. A fault is called hard or abrupt if its effects on the system are larger and bring the system very close to the limit of acceptable behaviour. A fault is called intermittent if its effects on the system are hidden for 
discontinuous periods of time. Although a fault is tolerable at the moment it occurs, it must be diagnosed as early as possible as it may lead to serious consequences in time.

A fault diagnosis system is a monitoring system that is used to detect faults and diagnose their location and significance in a system. The system performs the following tasks:

1. Fault detection - to indicate if a fault occurred or not in the system

2. Fault isolation - to determine the location of the fault

3. Fault identification - to estimate the size and nature of the fault

The first two tasks of the system - fault detection and isolation - are considered the most important. Fault diagnosis is then very often considered as Fault Detection and Isolation (FDI). A fault-tolerant control system is a controlled system that continues to operate acceptably following faults in the system or in the controller. An important feature of such a system is automatic reconfiguration, once a malfunction is detected and isolated. Fault diagnosis contribution to such a fault-tolerant control system is detection and isolation of faults in order to decide how to perform reconfiguration.

\subsection{Diagnosis based on analytical models}

The model based fault diagnosis can be defined as the determination of the faults in a system by comparing available system measurements with a priori information represented by the system's analytical/mathematical model, through generation of residuals quantities and their analyses.

When an analytical model is used to represent any system under diagnosis is that it cannot perfectly model uncertainties due to disturbances and noise. The differences provoked by the non-complete description of the model, cause the residual values, which are instruments to indicate faults. By Palade and Jain, a robust FDI scheme represents a FDI scheme that provides satisfactory sensitivity to faults, while being robust (insensitive or even invariant) to modelling uncertainties.

The principal challenge in designing a robust FDI scheme is to make it able to diagnose incipient faults. The effects of an incipient fault on a system are almost unnoticeable in the beginning, thus effects of uncertainties on the system could hide these small effects.

A fault diagnosis task consists of two main stages: residual generation and decision-making. Residual generation is a procedure for extracting fault symptoms from the system, using available input and output information. A residual generator represents an algorithm used to generate residuals. Decision-making represents examining the residual signals in order to establish if a fault occurred and isolate the fault.

Residual evaluation techniques are divided into threshold decisions, statistical methods, and classification approaches. In accord of Jain, residual evaluation techniques, offers the adequate conditions to classify the faults in a machine problem. Considering the work of German Munoz, the fusion of Artificial Neural Networks and Fuzzy Logic, can be applied to model, simulate and control, industrial processes like Power Generation, to predict fault in the scheduling and maintenance of turbo generators.

Fuzzy logic tools can also be applied for residual evaluation in the form of a classifier as to reduce the variability in the decision-making to prevent faults in machines as well. One 
possibility is the combination of this qualitative approach with a quantitative residual generating algorithm. This idea is an improvement at the Recursive Decision Feedback Extension (RDFE) method presented by Graciós et al (2005).

\section{An alternative fault tolerance model}

Considering the last concepts explained, an alternative method is proposed a Fuzzy Filter to improve the decision-making of a Recursive Decision Feedback Extension, presented by Graciós, Munoz, Diaz, Nuno-de-la-Parra \& Vega-Lebrúm (2009), which were applied to evaluate the possibility of fault and control of a real power generation plant. The fuzzy filter design is develop using the method described by Jain as follows.

\subsection{Method proposed}

The method proposed is based on the Recursive Decision Feedback Extension presented by Graciós (2009) and the Fuzzy Residual Evaluation embedded in a filter to diagnostic the soft fault generated in the behaviour of continuous function machines. In this paper, the principal solution is evoked at turbo generators in a hydro-plant.

To develop the improvement over the Recursive Decision Feedback Extension, we will invoke the concepts presented in early articles. Graciós, Vargas and Díaz (2005), have demonstrated that Fuzzy Logic (FL) and Artificial Neural Networks (ANN), can be used to transform quantitative knowledge (now residuals) into qualitative knowledge. This knowledge can be considered further information to evaluate the correct performance of the process for decision-making. Muñoz-Hernández et al (2009), presented a novel application of Neural PID to establish an adequate solution to control the behaviour in power and frequency for a hydro-plant. Perhaps the model is almost complete, the performance with the neural part, improved the result in simulation.

Considering the results obtained by the simulator, it is necessary to obtain a robust FDI because the decision-making in the output of the RDFE scheme is hard. The FDI can resolve the problem to "soft" the decision in terms of the type of faults that present in the generators.

PORT $>>$ Get [P1(t), P2(t), P3(t), P4(t)] for each machine (i)

$\mathrm{Z}[\mathrm{P} 1(\mathrm{t}), \mathrm{P} 2(\mathrm{t}) \mathrm{P} 3(\mathrm{t}), \mathrm{P} 4(\mathrm{t})]=[\mathrm{P} 1(\mathrm{k}), \mathrm{P} 2(\mathrm{k}), \mathrm{P} 3(\mathrm{k}), \mathrm{P} 4(\mathrm{k})]$

Fuzzyfing [P1(k), P2(k), P3(k), P4(k)]

For $\mathrm{i}, \mathrm{j}=1$ to $\mathrm{k}$ (data number)

$A\left(u_{i j}\right)=B(1)\left(f_{1 j}(u), f_{2 j}(u), f_{3 j}(u), f_{4 j}(u)\right) ;$

Intell_Sch=Max $\left[\operatorname{Min}\left[B\left(f_{1 j}\right)\left(f_{1 j}\left(u_{1}\right)\right), B\left(f_{2 j}\right)\left(f_{2 j}\left(u_{1}\right)\right), B\left(f_{3 j}\right)\left(f_{3 j}\left(u_{1}\right)\right), B\left(f_{4 j}\right)\left(f_{4 j}\left(u_{i}\right)\right)\right]\right.$;

End

PORT <<FF (Mesch);

Fig. 1. Improved RDFE algorithm.

Describing the method, the inputs of the Fuzzy Filter requires of the three basic components:

- $\quad$ Signals Fuzzified.

- Inference algorithm. 
- Classification of the fault indication.

The process of fuzzification have realised by RDFE. The inference algorithm is described by Munoz-Hernandez et al (2009), using the results obtained by neural PDF strategy. The weights of the ANN applied in the scheme, are used to refine the decision-making in the RDFE scheme.

Several improvements have been developed in the application technique. First the decision algorithm is soft by the use of the Filter, which is designed with the classification generated in the last paper. The fuzzification is well-defined in the concept outlined of the DFE implementation procedure obtained by Jain \& Martin (1998).

Jones and Mansoor (See Muñoz-Hernández:2009), have contributed in the state of the art of Instrumentation and Control of hydro-plant subsystem considering the possibilities in presence of faults. These concepts were applied in the design of the filter to present the classification of faults as a output of the method.

The FF function is a pseudo process to evaluate the hard decision obtained by the RDFE algorithm and the Filter "softens" the decision-making in the control strategy. PORT is an added function to MAP the digital values that arrives from and to the process using the adequate and confidence sensors a actuators.

\subsection{The algorithm}

The structural and functional description of the algorithm is based on the contribution presented by B. Köppen-Seliger and P. M. Frank. Their work is included in the book of Fusion of intelligent schemes (see Jain \& Martin: 1998), where the question: is it possible to distinguish between all defined faults using the given rules? is answered.

To answer this question in the case of turbo generators in a hydro-plant it is necessary to prove whether or not a distinction between the faults can be made.

The assumptions of the premises presented by Köppen-Seliger (in the same book of Jain \& Martin: 1998), are used to discriminate the possible faults in terms of 4 parametric behaviours for each turbo generator. The original algorithm was modified to represent the more possible faults for lead to the following description:

$f_{\mathrm{k}}$ occurs, but none of the other faults

To handle this with the algorithm, each rule has to be transformed into a fuzzy switching function defined by Jain. If the result of the fuzzy switching function is equal to 0.5 then the rule is fuzzy-consistent. If the result is $<0.5$ the rule is fuzzy-inconsistent. That means that for fuzzy-inconsistent rules the compatibility degree is $<0.5$ for all $x$.

The complete design algorithm has been summarized a recent work presented by Graciós (2009) in local conferences with good results and each step was developed as follows:

Step 1. Define the number of faults which are of interest.

In this step, the number of faults was obtained using the simulation platform described by German and collaborators in another In-tech Chapter of book where several simulations were realised to create an adequate Database for the fault definition. 
Step 2. For each residual component, two fuzzy sets have to be defined as an initial definition. These two fuzzy sets are normal and not normal. However, there is no definite rule about the suitable number of order partition, the higher the precision will be. But it will take more time in computing processing and more complicated form in modelling. Considering the results by the simulator, for the hydro plant is necessary 3 partitions only to improve and soft the decision making scheme.

The fuzzy sets obtained from the step 1 were defined using Fuzzy Time Series (FTS) as follows: let

$$
\mathrm{X}_{\mathrm{t}}^{\mathrm{u}(\mathrm{i})}=\{x[t, u(i)] \text { for } t=1,2, \ldots, \mathrm{n}\} \in R,
$$

Be a time series, $\Omega$ be the range of $\mathrm{X}_{\mathrm{t}}^{\mathrm{i}}$ for each $i$ parameter under measure of the $u$ machien and $P_{j}$, for $j=1,2,3, \ldots n$,

$$
\bigcup_{j=1}^{r} P_{j}=\Omega
$$

be an ordered partition $\Omega$. Let $\mathrm{L}_{j}$ denote linguistic variables with respect to the ordered partition set. For $t=1,2, \ldots, n$, if $\mu_{i, j}$, is the grade of membership (possibility of fault) of $X$ belongs to $L_{j}$, satisfies $u$. Then $\mathrm{FX}_{t} \mathrm{u}^{(i)}$ is said to be the Fuzzy Time Series for each $u(i)$ machine parameter and written as:

$$
\mathrm{FX}_{\mathrm{t}}^{\mathrm{u}(\mathrm{i})}=\mu(1) X_{t}^{u(2)} / \mathrm{L}_{1}+\mu(2) X_{t}^{u(2)} / \mathrm{L}_{2}+\mu(3) X_{t}^{u(3)} / \mathrm{L}_{3}+\mu(4) X_{t}^{u(4)} / \mathrm{L}_{4}
$$

where / is used to link the linguistic variables with their membership in FX, and the + operator indicates, rather than any sort of algebraic addition, that the listed pairs of linguistic variables and membership collectively.

In this approach, triangular membership function was selected for easy transformation process when the cacalculating corresponding membership functions of linguistic variables in FTS.

Step 3. The rules are transformed into fuzzy switching functions. As a simple example for this transformation consider the following rule:

If Res 1 is normal and Res 2 is negative or If Res 1 is positive and Res 2 is negative then $f 1$ the corresponding fuzzy switching function is given as the definition is based on the assumption that the first index indicates the residual and the second index indicates the fuzzy set of this residual.

Step 4. Based on the fuzzy sets defined in Step 3 and the faults defined in Step 1, the resulting number of rules has to be generated.

Step 5. Prove whether or not it is possible to distinguish between all faults. That means that the fuzzy switching functions have to be checked for phrases described by Equation (5). This procedure must be performed for all faults. This leads to the following scheme:

In this formula to check for faultk, just the terms for $k$ to $p$ are considered, because the previous steps checked that fault $k$ is fuzzy consistent with respect to fault $1, \ldots$, faultk-1. 
Step 6. If the distinction is possible, all faults can be detected and isolated and the procedure is terminated.

Step 7. If a perfect distinction with this choice of the distribution of the fuzzy sets is not possible, one or more fuzzy sets have to be modified. This means, for example, that instead of the fuzzy set "not normal" two fuzzy sets "slightly deviating" and "strongly deviating" may be discriminated. The fuzzy set that has to be changed is a result of the reduced switching function. It is the fuzzy sets that lead to a fuzzyinconsistency.

Step 8. Now carry out the algorithm again and repeat the procedure until a unique distinction is possible.

This algorithm ensures that all faults are detectable and distinguishable. If a perfect distinction of the residuals is not possible, the algorithm indicates these inconsistencies. This helps the operating personnel to evaluate signals giving consideration to the inconsistency. To prove the algorithm it was applied to a part of a wastewater plant.

There are two possible uses of the supporting algorithm for the design of the Fuzzy Filter in the residual evaluation process. The first possibility starts with an empty rule base. That means that the designer has to generate a complete rule base using this algorithm. This ensures that the generated rule base is consistent and complete with respect to the fault detection scheme. Therefore, all rules have to be consistent and unique in order to represent each fault under consideration. The suggested algorithm automatically checks whether or not these conditions are fulfilled.

The second possibility starts with a given, possibly inconsistent, rule base. The task is now to check which part of the given rule base is inconsistent and/or incomplete. This part of the rule base should be modified as described in the next section. It should be mentioned that these two possibilities use the same algorithm; just the initial conditions of these two possibilities are different. To use this algorithm, the so-called Fuzzy Switching Functions have to be defined in order to simplify the procedure.

\section{Case of application}

The hydropower generation process is a well-known industrial process that converts mechanic force into electric power. The conversion pathway of the process is shown in Figure 2. The output of the process is electrical energy where power and phase parameters are evaluated by performance index.

To run such an energy conversion process under efficient conditions, which means to reduce the probability of fault in the influence of electrical net, some requirements have to be met. To include all effects, the model of the process has to be highly nonlinear and of high order. Because of these facts some researchers have tried to simplify the model by reducing the number of subsystem parts in the process. The complete model contains three subsystems for the whole plant:

- $\quad$ Guided Vanes

- Hydraulic

- Electric 


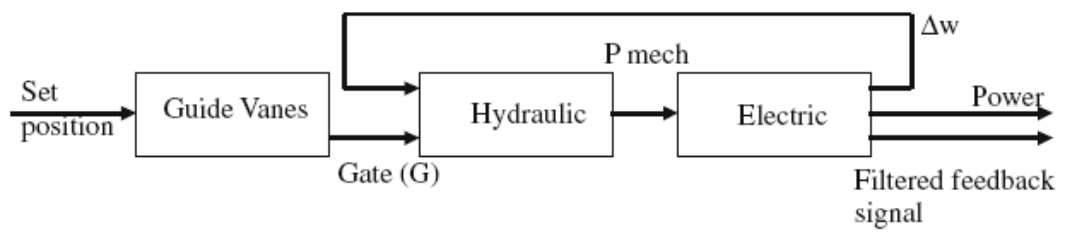

Fig. 2. The three subsystems of the hydroelectric plant.

Because electric subsystem is the most significant part some models contain just similar form of model. The complete model of the electrical subsystem (Fig. 3) is based on the 'swing' equations [20], and includes the effect of synchronizing torque. The first-order filter is included in the feedback loop for noise reduction. The models are expressed in the perunit system, normalized to 300MW and $50 \mathrm{~Hz}$.

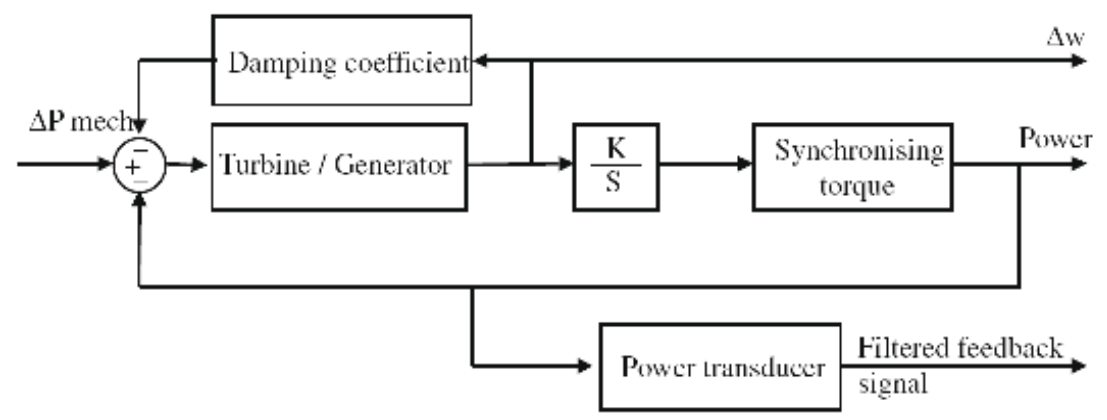

Fig. 3. Electric subsystem of the hydroelectric plant.

This model was implemented in Simulink@. It was designed to be scalable, allowing different behaviours to be selected according to the objective of the study. For the purposes of this work, a multivariable linear model was chosen.

\subsection{Design of the fuzzy filter for residual calculation}

The design of the fuzzy filter for the qualitative residual evaluation is based on the following assumptions:

- The structure of the fault diagnosis scheme is based on the topology described in Figure 4. This includes a nonlinear model of the process as well as a linear model for the observer-based residual generator.

- For the design of the fuzzy filter, only a qualitative description of the faults is needed.

- Both the quantitative residual vector and the qualitative description of the fault behaviour are used as inputs to the fuzzy filter in order to detect and isolate the faults (Fig. 4.).

As is described in the design method, the fuzzy filters are tuned using an array of Fuzzy Time Series to define the membership grades to identify and isolate the faults.

Steps 1 to 8 are developed as the original RDFE scheme is presented in [9], however the refine of the decision for each decision-making parameters is made coupling the Fuzzy Filters (FF) at the out of the scheme with the FEED evaluation from the $\mathrm{B}\left(u_{i}\right)$ adjusts. 
Step 9. Calculate the FF $\left\{B\left(u_{i}\right)\right\}$ for $i=1,2,3,4$.

The FF was implemented using MATLAB and tested using SIMULINK and the Simulator used in [10] to refine the decision in the environment.

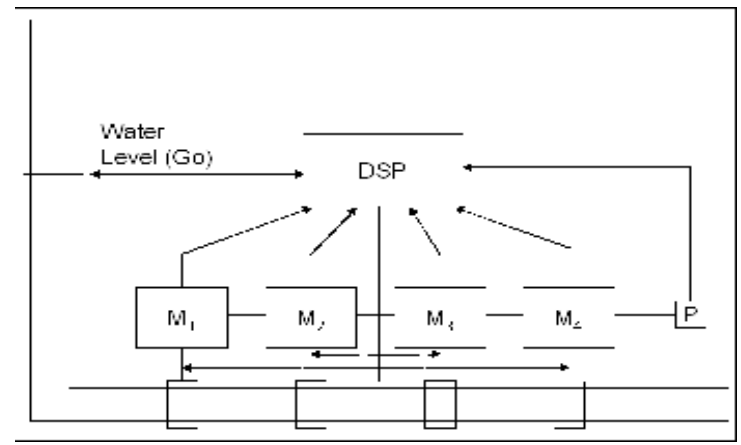

Fig. 4. Schematic for hydro-plant.

The simulated process is presented schematically in figure 4 . The initial values of each performance parameter $\left(f_{j}\right)$ by each machine $\left(u_{i}\right)$ and their corresponding membership function values $B\left(f_{i}\right)\left(f\left(u_{i}\right)\right)$ is given in the Table 1 .

\begin{tabular}{|c|c|c|c|c|}
\hline $\mathrm{u} / \mathrm{f}$ & P1 & P2 & P3 & P4 \\
\hline M1 & 0.86 & 0.91 & 0.95 & 0.93 \\
\hline M2 & 0.98 & 0.89 & 0.93 & 0.90 \\
\hline M3 & 0.90 & 0.92 & 0.85 & 0.96 \\
\hline M4 & 0.91 & 0.83 & 0.91 & 0.87 \\
\hline \multicolumn{5}{|c|}{ Fuzzy Parametrization } \\
\hline M1 & 0.6 & 1 & 1 & 1 \\
\hline M2 & 1 & 0.9 & 1 & 1 \\
\hline M3 & 1 & 1 & 0.5 & 0.7 \\
\hline M4 & 1 & 0.3 & 1 & \\
\hline
\end{tabular}

Table 1. Initial Average Performance and Fuzzy Membership.

When the procedure of fuzzification is developed, we get $A\left(u_{1}\right) \approx 0.6, A\left(u_{2}\right) \approx 0.9, A\left(u_{3}\right) \approx$ 0.5 and $A\left(u_{2}\right) \approx 0.3$. So, for this particular case $\mathrm{M}_{2}$ has the best performance of the four machines, where in this actual condition, can be considered has good functioning condition.

Now consider we propose a performance curve index to define the best schedule for the 4 machines in terms of the 4 parameters defined and then a novel algorithm can be developed for a recursive version for the DFE strategy.

Figure 5 is the result of the scheduling strategy without the Fuzzy Filter, reported by Graciós et al(2009), however, figure 6 shows the "soften" result in the scheduling of the performance for the 4 turbo generator considering the Fuzzy Filter designed.

Consider that several time intervals are found scheduling instability due the time of calculation for the tune filter scheme. This is a part to be improved in a future work. 


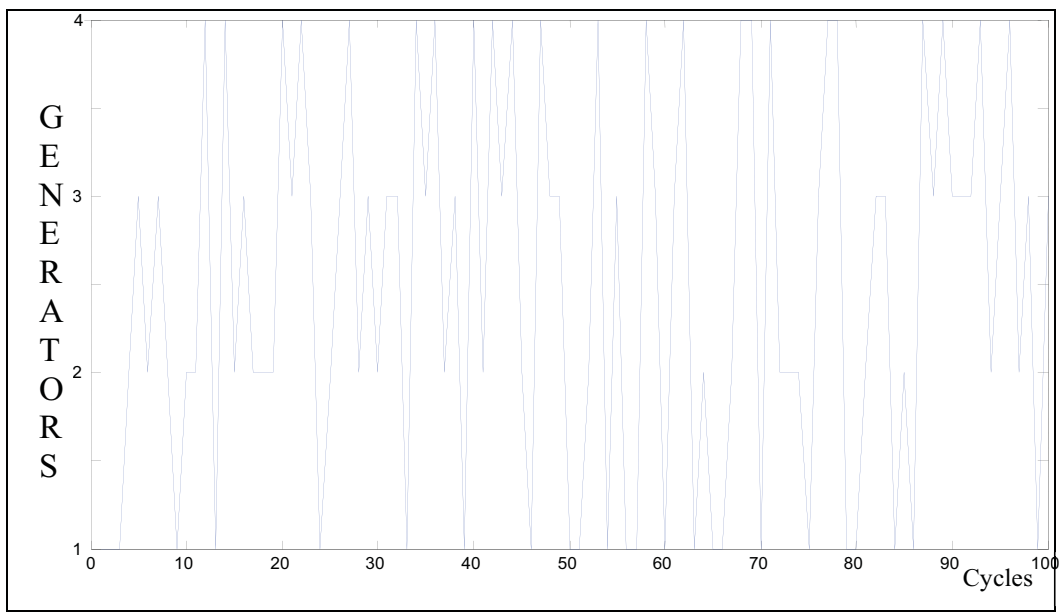

Fig. 5. Simulation of the scheduling for the plant without Fuzzy Filter.

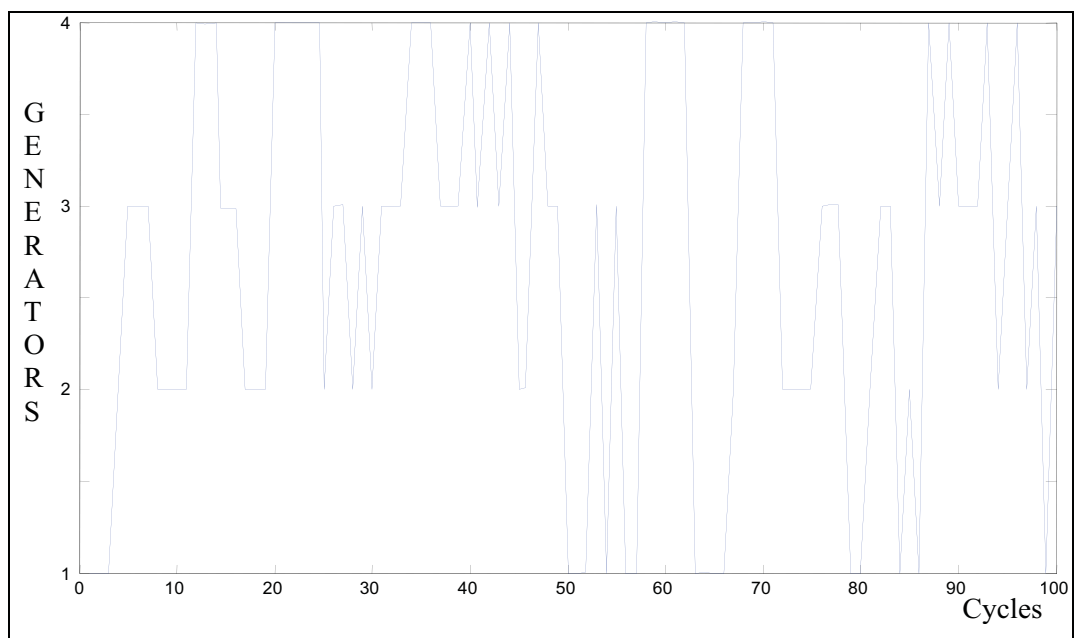

Fig. 6. Simulation of the scheduling for the plant with Fuzzy Filter.

This model was implemented in Simulink ${ }^{\circ}$. It was designed to be scalable, allowing different behaviours to be selected according to the objective of the study. For the purposes of this work, a multivariable linear model was chosen.

\section{Conclusions}

The theory of Fuzzy decision using Feedback extensions was introduced to determine a novel fuzzy scheduling scheme to be applied in the meet of production goal by a programmed performance. This type of schedule represents a novel alternative to transform typical industrial process on "intelligent process" inserting AI agents in the regulation/control of activities for each resource. 
It lets to improve the requirements of agility and fault tolerance for actual processes, where the agent can be developed using rapid prototyping architectures like FPGA as well.

With the inclusion of soften filters in the decision of performance evaluation, the graphs can shown, the improvisation of the stability decision in the performance of each turbo generator in a typical plan of 4/6 in Dinorwig hydroplant.

The use of the actual simulator presented by Muñoz-Hernandez et al (2009) in the validation of the performance represents an adequate form off line to protect the real system.

The soft parts developed by the fuzzy filters, reduce in a $40 \%$ the computational time for the scheduler considering a good value of $33.3 \mathrm{~ms}$ for each time of scheduling cycle.

The equations to calculate the membership for each fuzzy filter were described in a programmable device obtaining a total delay time of $1 \mathrm{~ms}$, which is affordable with the implementation of this type of application.

The practical results compared using Matlab® showed best performance in the function of the machines processes validating the possibility to recursive a basic feedback extension definition.

\section{Acknowledgment}

Carlos Arturo Gracios Marin wants to give thanks to Profs. Dewi I. Jones, Sa'ad Mansoor and German Muñoz by their advised, in the redaction of this work. My particular and great grateful, at the colleagues of the Academic Group of Power traction, quality and Generation of the Puebla Autonomous University (BUAP) and in special for Prof. Fernando Porras, Francisco Portillo and my special consideration to the support of Education and Postgraduate Offices of this Institution because without them, this publication has not been possible. Finally, I want to express my personal acknowledgment to Dr. Agüera (Rector of the University) and De la Peña Mena (Scientific Director of CONACYT) for your financial support in this project.

\section{References}

Cassandras, C. \& Lafortune, S. (2008). Introduction to Discrete Event Systems, Second Edition, Springer Science +Business Media LLC, ISBN 978-0-387-33332-8.

Dagli, C. H. (1994). Artificial Neural Networks for Intelligent Manufacturing, First Edition, Chapman \& Hall, U. K.

Graciós-Marín, C. A. ; Munoz-Hernandez, G. A. ; Diaz-Sanchez, A. ; Nuno-de-la-Parra, P. ; Estevez-Carreon, J. \& Vega-Lebrúm, C. A. (2009). Recursive decision-making feedback extension (RDFE) for fuzzy scheduling scheme applied on electrical power control generation, International Journal of Electrical Power \& Energy Systems, Vol. 31, Issue 6, pp. 237-242, Elsevier, U. K.

Graciós-Marín, C. A. ; Vargas-Soto, E. \& Díaz-Sánchez, A. (2005). Describing an IMS by a FNRTPN definition: a VHDL approach, International Journal on Robotics and CIM, Vol. 21, Issue 3, Elsevier.

Jain, L. C. \& Martin, N. M. (1998). Fusion of Neural Networks, Fuzzy Systems and Genetic Algorithms: Industrial Applications, ISBN 0849398045, CRC Press, CRC Press LLC. 
Munoz-Hernandez G. A.; Gracios-Marin C. A.; Diaz-Sanchez A.; Mansoor S. P. \& Jones D. I. (2009). Neural PDF Control Strategy for a Hydroelectric Station Simulator, In: Automation Control - Theory and Practice, A D Rodić (Ed.), ISBN: 978-953-307-039-1 Intech, Available from http://sciyo.com/articles/show/title/neural-pdf-controlstrategy-for-a-hydroelectric-station-simulator.

Nasr, E. A. \& Kamrani A. L. (2007). Computer-Based Design and Manufacturing: An Information-Based Approach, ISBN 0-387-23323-7, Springer Science+Business Media, LLC.

Palade, V. ; Bocaniala, C. D. \& Jain, L. (2006). Computational Intelligence in Fault Diagnosis Advanced Information and Knowledge Processing, ISSN 1610-3947.

Rzevski, G. (1989). Artificial Intelligence in Manufacturing, Computacional Mechanics Publications. Springer-Verlag, Proceedings of the fourth International Conference on the Applications of Artificial Intelligence on Engineering, Cambridge, U. K. July 1989.

Shen, W. \& Norrie D. H. (1999). Agent-Based Systems for Intelligent Manufacturing: A State-ofthe-Art Survey, Knowledge and Information Systems, an International Journal, 1(2), pp. 129-156.

Zhou, M. \& Venkatesh, K. (1999). Modelling, Simulation and Control of Flexible Manufacturing Systems.- A Petri Net Approach, Series in Intelligent Control and Intelligent Automation Vol. 6, World Scientific. 


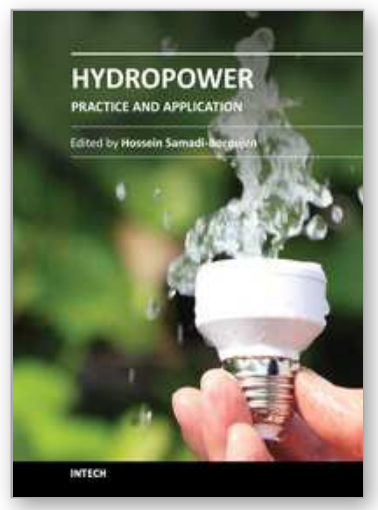

\author{
Hydropower - Practice and Application \\ Edited by Dr. Hossein Samadi-Boroujeni
}

ISBN 978-953-51-0164-2

Hard cover, 320 pages

Publisher InTech

Published online 09, March, 2012

Published in print edition March, 2012

Hydroelectric energy is the most widely used form of renewable energy, accounting for 16 percent of global electricity consumption. This book is primarily based on theoretical and applied results obtained by the authors during a long time of practice devoted to problems in the design and operation of a significant number of hydroelectric power plants in different countries. It was preferred to edit this book with the intention that it may partly serve as a supplementary textbook for students on hydropower plants. The subjects being mentioned comprise all the main components of a hydro power plant, from the upstream end, with the basin for water intake, to the downstream end of the water flow outlet.

\title{
How to reference
}

In order to correctly reference this scholarly work, feel free to copy and paste the following:

Carlos Gracios-Marin, Gerardo Mino-Aguilar, German A. Munoz-Hernandez, José Fermi GuerreroCastellanos, Alejandro Diaz-Sanchez, Esteban Molina Flores and Eduardo Lebano-Perez (2012). Fuzzy Scheduling Applied on Hydroelectric Power Generation, Hydropower - Practice and Application, Dr. Hossein Samadi-Boroujeni (Ed.), ISBN: 978-953-51-0164-2, InTech, Available from: http://www.intechopen.com/books/hydropower-practice-and-application/fuzzy-scheduling-applied-onhydroelectric-power-generation

\section{INTECH}

open science | open minds

\author{
InTech Europe \\ University Campus STeP Ri \\ Slavka Krautzeka 83/A \\ 51000 Rijeka, Croatia \\ Phone: +385 (51) 770447 \\ Fax: +385 (51) 686166 \\ www.intechopen.com
}

\author{
InTech China \\ Unit 405, Office Block, Hotel Equatorial Shanghai \\ No.65, Yan An Road (West), Shanghai, 200040, China \\ 中国上海市延安西路65号上海国际贵都大饭店办公楼405单元 \\ Phone: +86-21-62489820 \\ Fax: +86-21-62489821
}


(C) 2012 The Author(s). Licensee IntechOpen. This is an open access article distributed under the terms of the Creative Commons Attribution 3.0 License, which permits unrestricted use, distribution, and reproduction in any medium, provided the original work is properly cited. 